\title{
Metro Environmental Assessment and Analysis Based on Inclusive Design
}

\author{
Wenwen Shi \\ School of Cultural Communication and Design, Zhejiang University of Finance \& Economics Dongfang College, \\ Hangzhou, China \\ Email:20140512@zufedfc.edu.cn
}

How to cite this paper: Shi, W.W. (2021) Metro Environmental Assessment and Analysis Based on Inclusive Design. Journal of Transportation Technologies, 11, 412-425. https://doi.org/10.4236/jtts.2021.113027

Received: June 28, 2021

Accepted: July 19, 2021

Published: July 22, 2021

Copyright (c) 2021 by author(s) and Scientific Research Publishing Inc. This work is licensed under the Creative Commons Attribution International License (CC BY 4.0).

http://creativecommons.org/licenses/by/4.0/

\begin{abstract}
Under the background of accelerating urbanization, increasing aging population and decreasing fertility rate in China, all sectors of society eager for an elderly-and-children friendly environment. As public transportation, the metro is at the frontline. This article takes promoting the inclusive design of the metro environment as the research goal, inclusive design as the research perspective and progressive research as the research method. It analyzes the significance of the inclusive design of metro through pyramid theory, employs personas classification to define the inclusive group, and includes user journey to explore the touch-point of metro ride experience so as to propose a metro inclusiveness evaluation kit. With the help of the toolkit, six metro lines and 42 stations in Hangzhou were evaluated and analyzed by using the method of mobile ethnography. Based on the macro and micro analysis of horizontal comparison, it offers solutions to Hangzhou Metro's existing problems and optimizes the inclusive performance, which can provide direction for the evaluation and optimization of the inclusive design of domestic metro construction.
\end{abstract}

\section{Keywords}

Inclusive Design, Evaluation, Analysis, Metro Environment

\section{Introduction}

Inclusive design is not only a general way of enabling products and services to meet the needs of the customers as far as possible [1] but also a growing philosophical view [2]. With its development of more than 20 years, its connotation and extension are no longer limited to the maximum fair use of products, environment and services, and began to include situation of use needs under differ- 
ent factors such as culture [3]. Persad designed an analytical evaluation framework and found a way to evaluate the match between user sensory, cognitive and physical capabilities and the demands made on the user by the product [4]. However, Harding believes that the inclusive design approach for product design may not apply to traffic building space, so he uses the service design approach to analyze the contact design in the London Metro and employs the service level based model (Agent-based model) to evaluate the inclusion of subway contacts [5].

China's rail transit research has also ushered in a steady and rapid development. In particular, the signal system, big data, algorithms and train control have become some hot topics. However, despite the decade-long research and efforts made by Professor Dong [6] and China's Center for Inclusive Design Research, the general concept of inclusive design is still stuck in the "barrier-free design" stage [7], and the recognition of inclusive design hasn't been formed. And the metro space research, inclusive design, and user research are isolated, with cross-synthesis. In particular, there are no appropriate tools or evaluation measures in evaluating the inclusiveness of the environment. This paper takes the inclusive design of the Hangzhou metro environment as an example, designs and assesses the evaluation methods to clarify the current situation and deficiencies of the inclusive design of the urban metro, and provides the basis for the optimization of inclusive design.

\section{Triggering Elements for Inclusive Design}

\subsection{Urbanization and the Aging Society Are in Parallel}

Data show that between 2010 and 2020, the urban population structure of Hangzhou changed dramatically. In 2019 , the total permanent resident population reached 10.36 million, increased by $28 \%$ from the end of 2009; the population over 60 accounted for $19.9 \%$, which means Hangzhou is under urbanization yet entering the aging society. Inclusive design can effectively enhance the ability of the elderly so as to live independently, while promoting the integration of social and economic exchanges of groups, and alleviate the contradiction between urbanization and population aging.

\subsection{International Events Push to Upgrade the Transportation System}

In order to facilitate the 2022 Asia (Paralympic) Games, Hangzhou Municipal Government has increased investment in rail transit. A total of 13 lines along the general rail line, rail express line and municipal lines will be completed, and the urban rail transit network with a total length of 516 kilometers and fully covering ten urban areas will be realized. In June 2020, Hangzhou Municipal Government issued the Action Plan for Barrier-free Environment Construction of Hangzhou "Welcome Asian (Para) Games", which officially put the three-year barrier-free environment optimization on the agenda. The host of international 
events often leads to the attention in planning and constructing of sports facilities [1].

\subsection{Blank of Metro Inclusive Design Standard}

In 2018, the British Standards Association issued the BS8300:2018 Accessibility and Inclusive Building Environment Design Guidelines, which advocated serving diverse needs of people in all aspects including the public transport infrastructure. Unfortunately, in China there is no such national standards for inclusive or accessibility design in rail transit, besides Metro Design Code (GB 50157-2013) and Barrier Design Standard (GB50763-2012); it has not yet issued a local standard related to metro inclusive design in Hangzhou [8]. In addition, the target users projected by the barrier-free design, such as the elderly group and the disabled group [9], other groups are not taken into consideration, but these groups also have a niche market [10].

\section{Methodology}

\subsection{Overview of Inclusive Design}

"Inclusive Design" was first proposed by British scholar Coleman in a Canadian conference in 1994. So far, enterprises, government and schools launched interdisciplinary inclusive design inquiry projects and cooperation, incubated a variety of inclusive design ideas, methods, views, academic works and achievements. The development of inclusive design eventually prompted the British reform from top to bottom: the inclusive design application and implementation code for urban transportation, urban planning, the large activities (Olympic Games) has a far-reaching impact.

\subsection{Research Method and Process}

Taking metro is a complex process, which involves a single or multiple trip experience, such as environmental adaptation, facilities use, information cognition and other aspects. Therefore, it seems impossible to assess metro inclusive design in one way, requiring a more systematic approach [11], thus a progressive user experience research approach centered on inclusive design has emerged at the moment.

\subsubsection{The Three Pyramid Theory \\ User Pyramid}

Swedish engineering team Benktzon proposed the user pyramid [12], dividing users into three categories based on limb damage and Motion Capability (MC), namely people with average MC at the bottom of the pyramid, people with moderate MC in the middle of the pyramid, and people with low MC at top of the pyramid. It helps designers to define different users so as to design more inclusive products, see Figure 1.

\section{Segmented Pyramid}




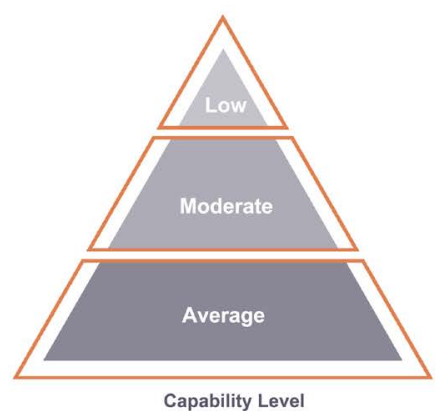

Figure 1. Three pyramids.
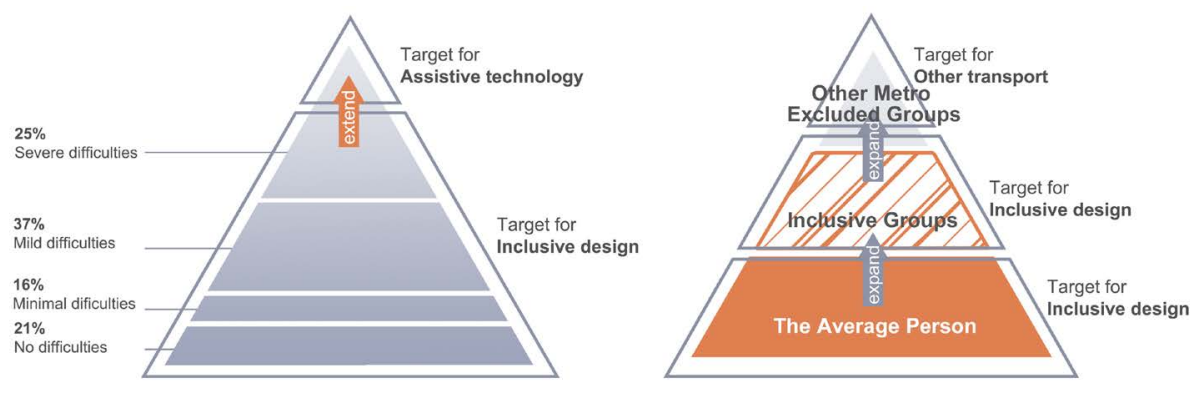

Based on the 2003 Microsoft research, Hosking and his group of the Cambridge Engineering Center drew the segmented Pyramid, noting that the purpose of inclusive design is to extend the scope of mainstream products as far as the pyramid as possible while maintaining commercial viability without compromising the design at the bottom of the pyramid [13], see Figure 1.

\section{Metro User Pyramid}

The author has proposed the pyramid of metro users to express the significance of inclusive design. First, passengers on the metro include ordinary people and "inclusive groups". The inclusive group is defined as all kinds of people with temporary, permanent and situational obstacles, which beyond the groups of the elderly and disabled. The significance of metro inclusive design lies in eliminating obstacles through the inclusive design of the metro, making the metro ride process convenient, comfortable and equal, so that more people choose the metro, thus to effectively expand the population of metro users, and generate a benign revenue, see Figure 1.

\subsubsection{Role Classification (Personas)}

Inclusive user groups of the metro, including the elderly, children, the disabled, the sick, new-comers, parents with kids to care, baggage carriers, pregnant women and sexual minorities (LGBT). Each group of population can be divided into several subgroups, each performing differently in three-dimensional [14]: Sensory Capability (SC), Cognitive Capability (CC) and Motion Capability (MC) and demanding inclusive facilities. At the same time, through 247 online questionnaire survey collection and qualitative analysis, the key considerations of the ability label of inclusive users and inclusive design of the metro are obtained. It is worth noting that the role classification is not absolute, for the following main reasons:

- There are several ways of classifying the subgroups.

- The ability of users has a compensation effect, and the ability level is multifaceted, and affects [1], such as blind people who lose vision usually have very keen hearing.

- There are possibilities with multiple lack of capacity [15], such as patients with Alzheimer's disease (cognitive disorder) usually with complications of mobility disorder. 
- This user analysis method can be used to describe ubiquitous features throughout the population, but the fidelity will decrease [16].

Nevertheless, the sub-user group classification method has managed to obtain the capability characteristics of typical users with reference value, and identify the key points of inclusive design, as shown in Figure 2.

\subsubsection{Journey Map}

In the early research, some scholars have initially raised the idea that service design can promote inclusive design, and analyzed the activities of taking London Underground through user journey [17].Based on their ideas, this study analyzes the process of each inclusive group, so that the main touch points of the inclusive design are summarized, as shown in Figure 3.

The idea of user journey is as follows:

Step one, determine the selected population. They should be the typical inclusive groups within each subgroup in the inclusive population category, represented by different colors. Step two, divide the activity stages. Metro ride activities(without transfer) can be separated into five parts, enter the station, reach the platform, take the metro, leave the platform and exit the station, according to the activity places. Step three, determine the touch-point of each stage. For example, the stage of enter the station includes location, entering, take the stairs/escalator, take the elevator, take the passage and other touch-point. Step four, a preliminary analysis: analyze whether each touch-point of each journey is inclusive and documented accordingly.

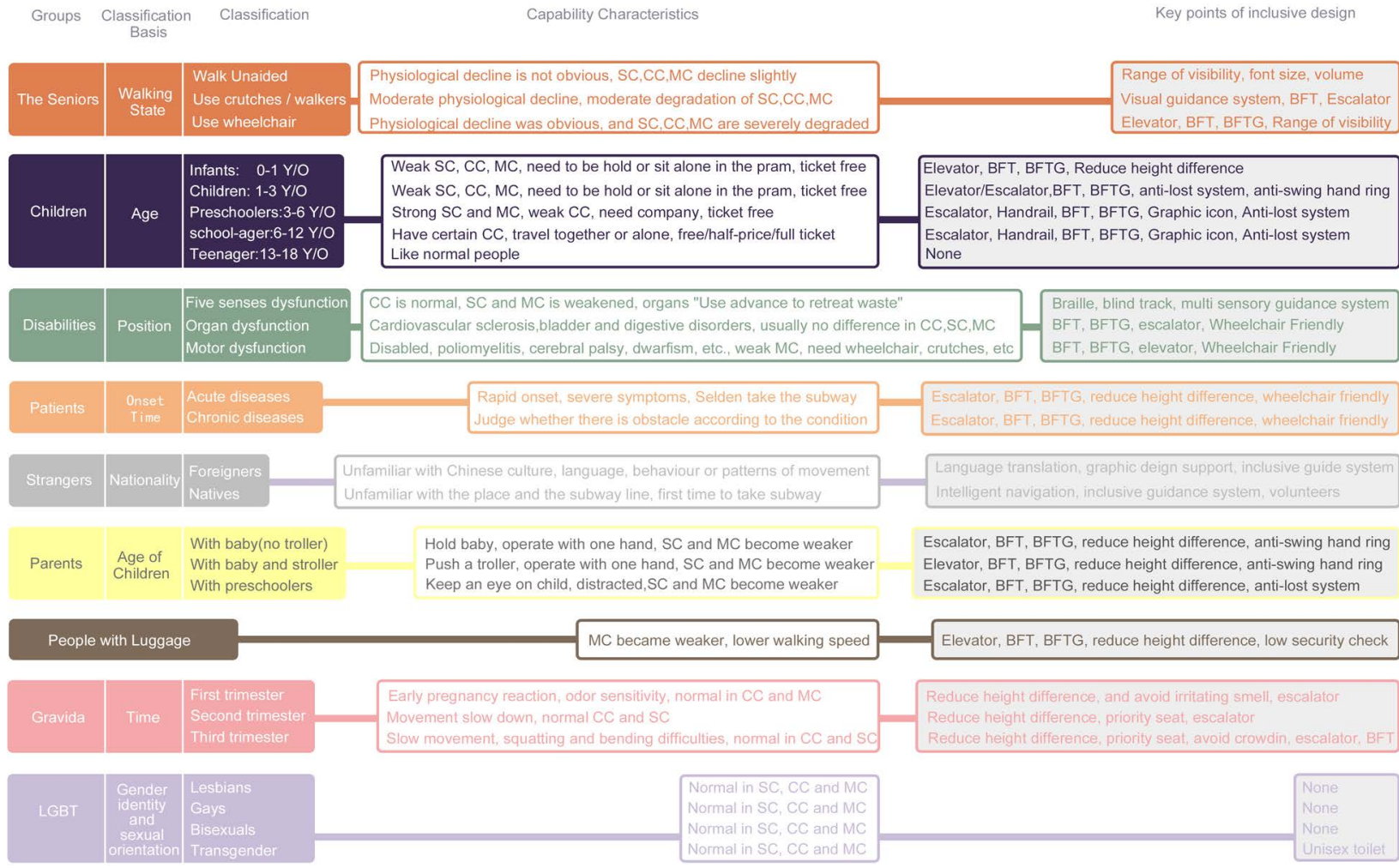

Figure 2. Personas classification label. 


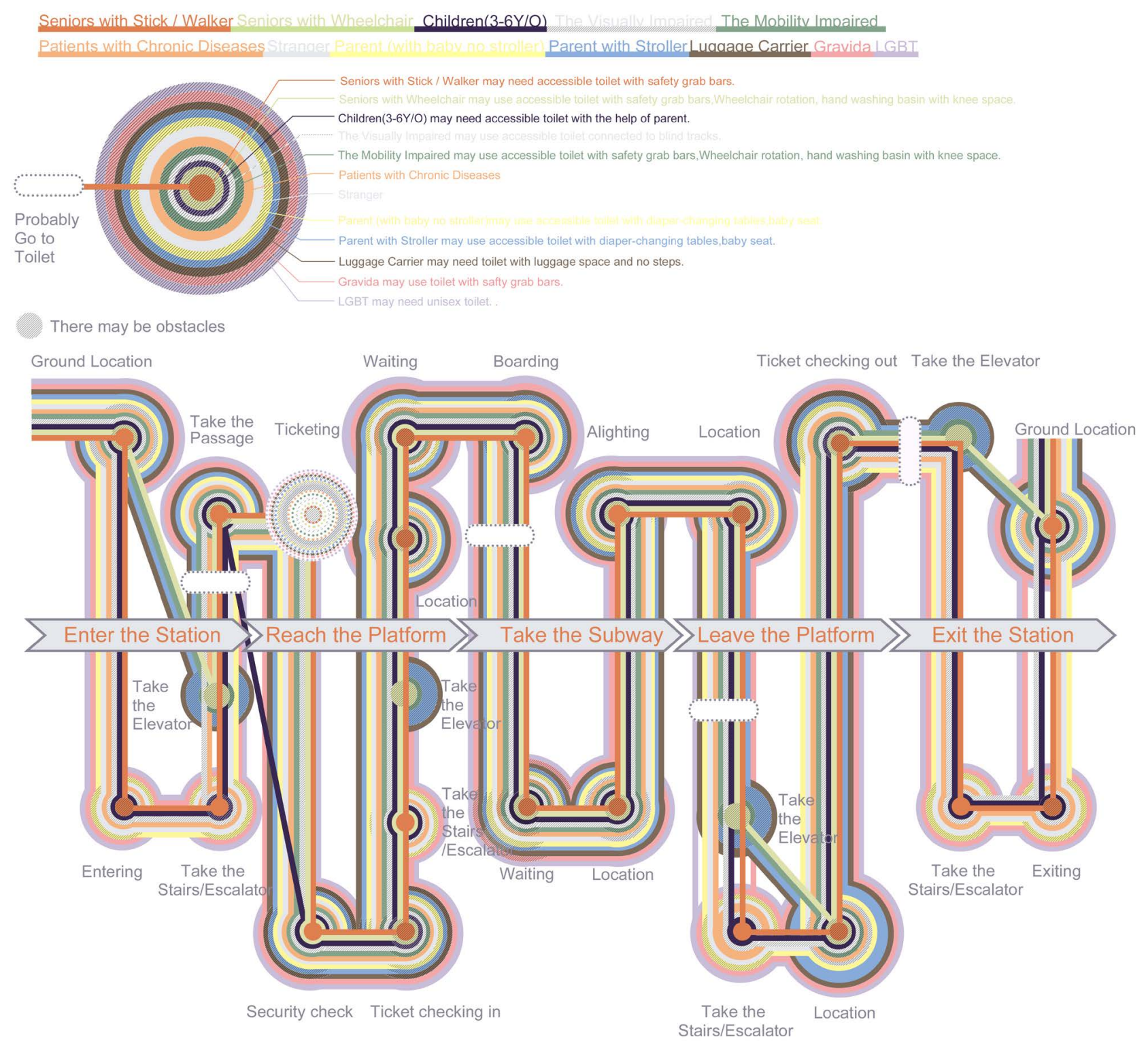

Figure 3. Map of inclusive group's journey.

The following information is concluded from Figure 3:1) The journey and the touch-points of each inclusive group are different; 2) each group has demands for each touch-point. It is worth mentioning that, compared with the foreign metro ride experience; the touch-points of the Chinese metro are slightly different as follows:

- Options in buying tickets: with the popularity of mobile payment, more and more passengers choose mobile phone payment, thus omitting the touch-point of machine or manual tickets [18];

- Health code display: under the pressure of epidemic prevention and control, it is the necessary steps to show the health code before taking the metro;

- Necessity of security check: to ensure a safe ride environment, it is also the necessary steps to scan the luggage and items to the security check instru- 
ment.

Of course, the user's journey only represents the journey path and the resulting contacts in the high probability of the crowd, which is not absolute.

\subsection{Metro Inclusive Design Assessment Kit}

How to scientifically evaluate the inclusive performance of products, the environment, or services has always been a direction of research committed by scholars at home and abroad, the Engineering Design Centre of Cambridge proposed "Design Wheels" in long-term research, integrate exploration, creation, evaluation, and even management into the inclusive design cycle to expose more basic activities about the concept of inclusive design. During the evaluation phase, the Center established a set of product exclusion computation methods [19], and subsequently developed an exclusion calculator to quantify inclusiveness from five evaluation dimensions, that is Mobility, Reach \& Dexterity, Vision, Hearing, and Thinking [20].

The idea of the Metro Inclusive Design Assessment Kit (hereinafter referred to as the toolkit) is inspired by the exclusion calculator and post-use evaluation method (POE), in the form of Lickett Quscale, with the user journey as the main axis, the contact as the evaluation unit and the detailed rules from perspective of various inclusive groups, requiring the appraisers to objectively evaluate the specific evaluation environment, facilities and services.

The toolkit is divided into 6 sub-forms, they are enter the station, reach the platform, take the metro, leave the platform and exit the station, ticket and toilet, and the first five sub-forms correspond to the five activities of the user's journey. The object measured by each sub-form is the contact generated by the user's journey, respectively. The evaluation standard is divided into qualitative standards and quantitative standards. Among them, the description of nature is explained in detail through comments, and the evaluation with numerical requirements is classified as quantitative standard. The appraisers can make detailed interpretation of the evaluation through comments, and attach drawings for reference. The toolkit requires the appraiser to evaluate the assessment items according to the actual situation observed and measured, and tick the five scale, finally link the option results to the score $(1-5)$, and finally conduct data analysis. The higher the score, the better the inclusive design and vice versa. See Figure 4 for the toolkit page.

\subsection{Mobile Ethnography}

Based on Auto-ethnographic method, the research team divided into 7 groups conducted the metro inclusive design assessment by using the toolkit, in January 2021.

First of all, the author led the team to Hangzhou Metro Line 1 Jiuhe Station to demonstrate the way of inclusive design assessment and emphasize the requirements of assessment, that is objectivity, content with details, evaluation basis, 


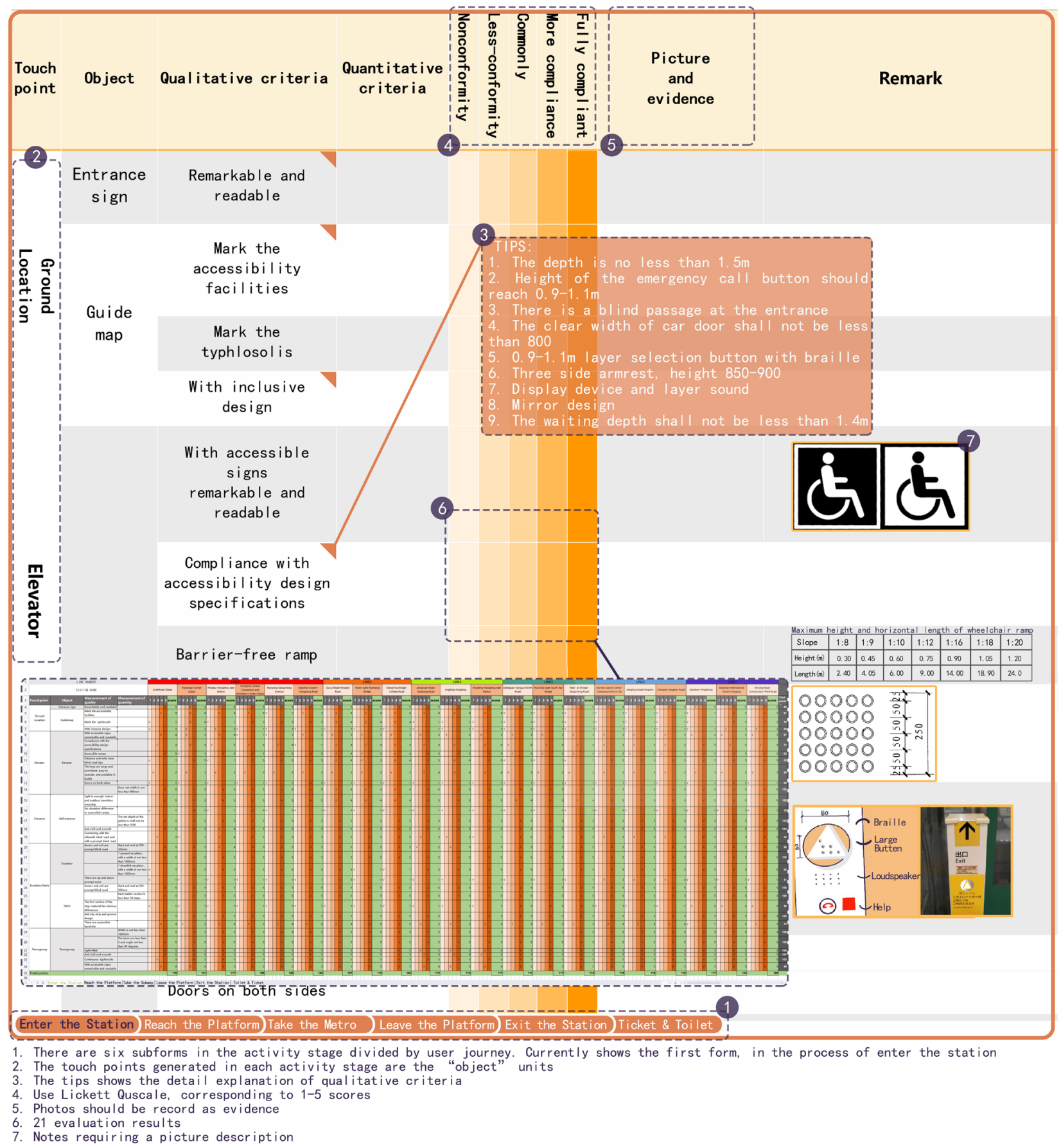

Figure 4. Interface of the metro inclusive design assessment toolkit.

evaluation methods, etc. Next, the team members are asked to carry evaluation kits, smartphones, measuring tools to evaluate a target metro line. Each team is responsible for the six stations. They take the ride from one station and exit from the next station, excluding the transfer factor, so each assessment contains three pairs of stations. During the assessment, the evaluator uses his or her smartphone whenever possible to collect evidence photos and take images to record and gain insights of his or her own. 


\section{Case Analysis}

\subsection{Data Description}

Based on the implementation of 21 evaluation results, we made detailed sorting and objective analysis, and obtained the data analysis figure as follows, see Figure 5. The right half of the analysis chart marks the evaluation map of the evaluators, where the yellow center is the starting station and the purple center is the end station. 3 groups of stations of each line are randomly selected for evaluation, including a large operation time span of the east section of Line 1 (Operated in November 2012) and Binjiang section (Operated in December 2020), so three more groups are added. The evaluation scope is basically carried out along the Qiantang River, and the total score of inclusive design of each group of stations is also marked on the evaluation map. On the left of the analysis chart is a statistical chart, showing the average score value of each line and the score value distribution column chart of each station group.

\subsubsection{Distribution Description of the Station}

The average score of the metro station group assessed was 598, a maximum score of 649 (Xiaoshan International Airport Station-Xingang Station Group) and a minimum score of 505 (Jiuhe Road Station-Qibao Station Group). The 590 (including)-610 fraction segment was most centralized with 7 groups. The result shows that the score of each station group is in a normal distribution curve. The number of pair of stations of high score segments decreases layer by layer, and the number of low score segments is scattered and equally scattered.

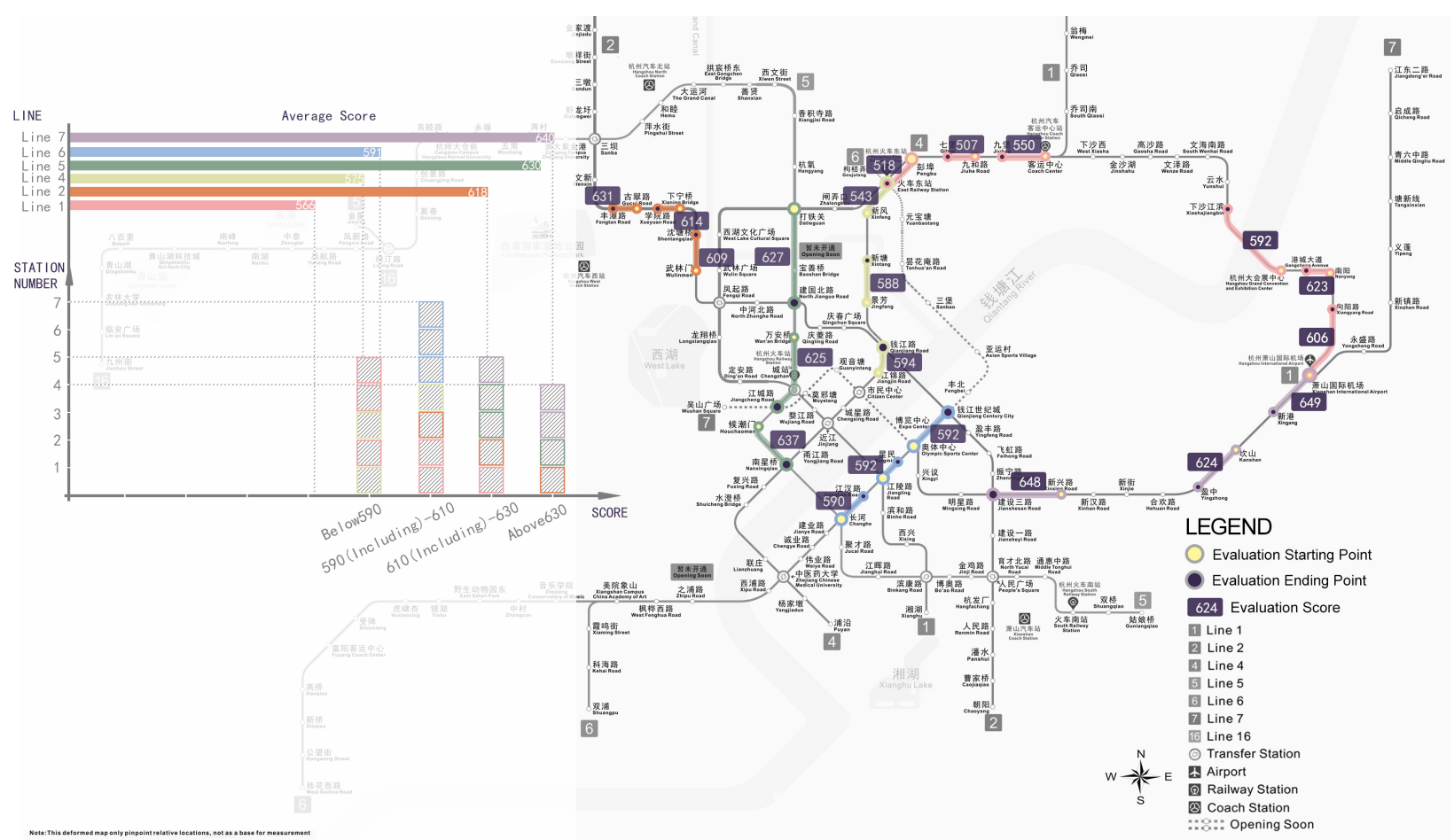

Figure 5. Assessment map (revised from Hangzhou Metro Line Map). 


\subsubsection{Average Score for Each Line}

As shown in Figure 5 above, the average score of the sampled line is 640 (Line 7) and the minimum 565 (Line 1); the average score from high to low are line 7 , Line 5, Line 2, Line 6, Line 4 and Line 1 respectively.

\subsection{Macro-Analysis Conclusions}

Conclusion 1: The inclusiveness of Hangzhou metro environment is increasing.

The degree of inclusiveness of Hangzhou metro is a dynamic process. This proves that the inclusiveness of Hangzhou Metro is not static, as shown by: First, the degree of inclusiveness of the same line is constantly improving. The authors conducted research on Line 1 in August 2017, July 2018, January 2020 and January 2021, and found that both hardware and software inclusive design have been improved; Statistically, the three lines with the highest average score are Line 7 (Operated in December 2020), the south-east section of Line 2 (Operated in December 2017) and Line 5 (Operated in June 2020), which are closely related to the opening time, and the later the line is opened, the more in-depth the consideration of inclusive design. The process of dynamic improvement fits well with the philosophical values of "inclusive design": designing for as many people as possible to remove barriers and iteration and refinement.

Conclusion 2: Although the experience feeling varies from person to person, the subjective error is small.

Inclusive assessment complies with the "heterogeneity" of service design, where the assessment experience can vary from time and person. In the randomly selected site evaluation, two pairs of appraisers selected the same stations, Xiaoshan International Airport Station and East Railway Station. In the evaluation of East Railway Station, since the evaluation object is a transfer station, the two appraisers assessed the same activity with the score of 114 (Line 1) and 127 (Line 2), detailed comparison of the assessment error resulted in the qualitative evaluation, including the "ambient light" option and Line 1 checked the "experience"; the score of Xiaoshan International Airport Station were 128 (Line 1) and 133 (Line 7). Although there are errors, the difference is not obvious due to the objectivity of the environment.

\subsection{Transverse Microscopic Analysis}

The inclusiveness of the same environment and facilities between different sites is also worthy of comparative analysis. The following table lists the six sub-forms with the lowest scores in six activity stages. From the results, the score of 21 points indicates that all stations do not meet the requirements and need to be improved; if the score is above 21 points, it means some stations did something on inclusive design but incomplete or poor for some reason; some problems occur repeatedly in the evaluation process due to standardized design and construction of the metro, see Table 1. 
Table 1. Three assessments with the lowest score per activity stage.

\begin{tabular}{|c|c|c|c|c|}
\hline Sub-forms & Touch point & Object & Assessment criteria & Score \\
\hline \multirow{5}{*}{$\begin{array}{l}\text { Enter the } \\
\text { station }\end{array}$} & $\begin{array}{l}\text { Ground } \\
\text { location }\end{array}$ & $\begin{array}{l}\text { Elevator } \\
\text { guide map }\end{array}$ & $\begin{array}{l}\text { Provided with inclusive design } \\
\text { features }\end{array}$ & 29 \\
\hline & Elevator & Elevator & Doors on both sides & 29 \\
\hline & Entrance & Entrance & $\begin{array}{l}\text { No elevation difference or } \\
\text { accessible ramps }\end{array}$ & 29 \\
\hline & \multirow{2}{*}{ Escalator/Stairs } & Escalator & $\begin{array}{l}\text { Provided with voice guide for up } \\
\text { and down }\end{array}$ & 31 \\
\hline & & Stairs & $\begin{array}{l}\text { The material of the first step has } \\
\text { obvious differences }\end{array}$ & 36 \\
\hline \multirow{4}{*}{$\begin{array}{l}\text { Reach the } \\
\text { platform }\end{array}$} & Location & Platform guide map & Marked with barrier-free routes & 21 \\
\hline & Ticketing & (Barrier-free ticket & $\begin{array}{l}\text { Provided with voice guide for pass } \\
\text { and the direction of escalator }\end{array}$ & 24 \\
\hline & & & Lower than the normal gate & 25 \\
\hline & Location & $\begin{array}{l}\text { Platform } \\
\text { guide map }\end{array}$ & $\begin{array}{l}\text { Provided with voice guide for } \\
\text { typhlosolis }\end{array}$ & 25 \\
\hline \multirow{3}{*}{$\begin{array}{l}\text { Take the } \\
\text { metro }\end{array}$} & Waiting & $\begin{array}{l}\text { Wheelchair } \\
\text { parking space }\end{array}$ & Guide maps for Low View Position & 24 \\
\hline & \multirow[t]{2}{*}{ Location } & $\begin{array}{l}\text { Map of the } \\
\text { metro carriage }\end{array}$ & $\begin{array}{l}\text { There are graphical design for each } \\
\text { station }\end{array}$ & 36 \\
\hline & & (Above the gate) & Striking code for each station & 40 \\
\hline \multirow{9}{*}{$\begin{array}{l}\text { Leave the } \\
\text { platform }\end{array}$} & \multirow{3}{*}{ Location } & \multirow{3}{*}{$\begin{array}{l}\text { Platform } \\
\text { guide map }\end{array}$} & Guide maps for Low View Position & 21 \\
\hline & & & With typhlosolis & 21 \\
\hline & & & With inclusive design & 21 \\
\hline & Elevator & Elevator & Doors on both sides & 21 \\
\hline & $\begin{array}{l}\text { Ticket } \\
\text { checking out }\end{array}$ & BFTG & $\begin{array}{l}\text { Provided with voice guide for pass } \\
\text { and the direction of escalator }\end{array}$ & 21 \\
\hline & \multirow{2}{*}{ Location } & Platform & Marked with barrier-free routes & 27 \\
\hline & & guide map & Supported with inclusive facilities & 27 \\
\hline & Escalator/Stairs & Escalator & Provided with voice guide & 27 \\
\hline & $\begin{array}{c}\text { Ticket } \\
\text { checking out }\end{array}$ & BFTG & Height below the normal gate & 33 \\
\hline \multirow{5}{*}{$\begin{array}{l}\text { Exit the } \\
\text { station }\end{array}$} & Elevator & Elevator & Doors on both sides & 21 \\
\hline & Escalator/Stairs & Escalator & Provided with voice guide & 21 \\
\hline & Exit & Station hall exit & $\begin{array}{l}\text { No elevation difference or within } \\
\text { accessible ramps }\end{array}$ & 33 \\
\hline & \multirow{2}{*}{ Location } & \multirow{2}{*}{$\begin{array}{l}\text { Platform } \\
\text { guide map }\end{array}$} & With typhlosolis & 33 \\
\hline & & & With inclusive design & 36 \\
\hline \multirow[b]{2}{*}{ Ticket \& toilet } & \multirow[b]{2}{*}{ Ticketing } & \multirow[b]{2}{*}{ Ticket machine } & With inclusive design & 24 \\
\hline & & & $\begin{array}{l}\text { Easy to operate for people with } \\
\text { different visual height }\end{array}$ & 27 \\
\hline
\end{tabular}




\begin{tabular}{lllc}
\hline & With typhlosolis & 27 \\
Toilet & (Unisex toilet, UR) & $\begin{array}{l}\text { An guide map with inclusive } \\
\text { design at the entrance }\end{array}$ & 34 \\
\hline
\end{tabular}

\subsection{Dire4.4. Dir4.4. Directions for Optimization}

Based on the result of the evaluation data, the author summarizes the problems and optimization direction of the Hangzhou metro lines into the following aspects:

- First, the planning of the new line should take inclusive design into consideration, while at the same time; the old line of Human-centered optimization should be noticed.

- Second, the height difference setting for the entrance and exit of metro should be removed. Design specifications stipulate that the entrance of the metro station must be set three steps of height, in order to prevent rainwater pouring. However, this criterion is still worth discussion. An inlet slow slope and drainage devices can be built to prevent rainwater; nonetheless, the avoidance of height-difference for accessible entrance is significant.

- Thirdly, the inclusive design of the guide system should be considered. Almost all guide maps in the metro station are presented in a single visual transmission way. We suggest integrating the expression of touch, voice prompts, graphic symbols, combined with the blind road and low vision design to provide possibilities for independent travel for inclusive groups.

- Fourthly, the inclusive improvement of BFTG. The survey found that the relevant departments have optimized the appearance of the BFTG, more conspicuous than the ordinary gate. Therefore, the author suggests that metro inclusive facilities should be distinguished by uniform design colors; the number and height of BFTG of new metro stations should be required and adjusted to fascilitate wheelchair, children and the elderly and add induction system to provide sound assistance.

- Fifthly, the inclusive optimization of other facilities and the environment. For example, the seats in the platform waiting area should be provided with handrails, and the height of seats should be uplift for the elderly. We also suggest to set coding system [8] and add icon design to increase the readability of the guide map, which can provide convenience for preschool children, elderly and foreigners. It is also suggested to enhance the systematization of the blind road, set prompt blind road before the inclusive facilities; incorporate the optimization design of UR, straight ladder in planning and design, such as opening mode and door button design.

\section{Conclusions}

This study emphasizes that metro lead users are diverse, with differences in MC, SC, and CC that largely affect their subway experience and may lead to design 
exclusion.

This study also shows that the inclusive design of the metro space can be quantitatively evaluated. The metro inclusive assessment toolkit has been established through the definition of inclusive design and methods of service design. The result shows that there is still large room for improvement in the inclusive design of Hangzhou metro. With the accumulation of metro construction experience, the technical breakthrough and the improvement of the design, the inclusiveness of subway space is also constantly improving. At the same time, the inclusive renovation of the old line also needs to be put on the agenda.

\section{Conflicts of Interest}

The author declares no conflicts of interest regarding the publication of this paper.

\section{Fund Project}

Hangzhou philosophy and social science planning project (M20JC066).

\section{References}

[1] Clarkson, P.J. and Coleman, R. (2015) History of Inclusive Design in the UK. Applied Ergonomics, 46, 235-247. https://doi.org/10.1016/j.apergo.2013.03.002

[2] Johnson, D., Clarkson, P.J. and Huppert, F. (2010) Capability Measurement for Inclusive Design. Journal of Engineering Design, 21, 275-288.

https://doi.org/10.1080/09544820903303464

[3] Dong, H. (2020) Introduction to Inclusive Design. Design, 15, 15.

[4] Persad, U., Langdon, P. and Clarkson, P.J. (2007) Characterising User Capabilities to Support Inclusive Design Evaluation. Universal Access in the Information Society, 6 , 119-135. https://doi.org/10.1007/s10209-007-0083-y

[5] Harding, J. (2019) Using Agent-Based Modelling to Probe Inclusive Transport Building Design in Practice. Urban Design and Planning, 172, 111-123. https://doi.org/10.1680/jurdp.18.00028

[6] Zhang, K. and Zhu, B.W. (2021) Research Progress, Hot Spots and Development Trend of Inclusive Design. Packaging Engineering, 42, 64-69+103.

[7] Dong, H. (2020) Inclusive Design: China and UK Comparison. Design, 15, 56-58.

[8] Shi, W.W. (2020) Research on Optimization Strategies of Inclusive Design of Hangzhou Metro. Urban Transport of China, 6, 75-83+17.

[9] Hu, F. and Zhang, X. (2017) Design for Aging: The Emergence and Evolution of Design Concepts for the Elderly since 1945. Journal of Nanjing Arts Institute (Fine Arts \& Design), 6, 33-44+235.

[10] Liu, C.S. and Yan, A.Q. (2015) Long Tail Effect and Value of Inclusive Design. Journal of Donghua University (Social Sciences), 15, 68-71.

[11] Terry, E. (2018) Transition Design: Design of System Level Change. Decoration, 10, $12-22$.

[12] Benktzon, M. (1993) Designing for Our Future Selves: The Swedish Experience. Applied Ergonomics, 24, 19-27. https://doi.org/10.1016/0003-6870(93)90155-3

[13] Hosking, I., Waller, S.D. and Clarkson, P.J. (2010) It Is Normal to Be Different: Ap- 
plying Inclusive Design in Industry. Interacting with Computers, 22, 496-501. https://doi.org/10.1016/j.intcom.2010.08.004

[14] Keates, S. and Clarkson, P.J. (2003) Countering Design Exclusion: an Introduction to Inclusive Design. Springer, London. https://doi.org/10.1007/978-1-4471-0013-3

[15] Waller, S.D., Langdon, P.M. and Clarkson, P.J. (2010) Designing a More Inclusive World. Journal of Integrated Care, 18, 19-25. https://doi.org/10.5042/jic.2010.0375

[16] Goodman-deane, J., Waller, S.D., Latham, K., Price, H., Tenneti, R. and Clarkson, P.J. (2016) Differences in Vision Performance in Different Scenarios and Implications for Design. Applied Ergonomics, 55, 149-155.

https://doi.org/10.1016/j.apergo.2016.02.001

[17] Harding, J., Luck, R. and Dalton, N. (2016) Journeys in the City: Empathising with the Users of Transport Buildings. In: Emmitt, S. and Adeyeye, K., Eds., International Conference on Integrated Design Building Our Future, University of Bath, Bath, 324-335.

[18] Li, Y.H. and Dai, D. (2019) A Study on Physical Contacts of Subway Service Design Based on Passenger Behavioral Trajectory Map. Packaging Engineering, 40, 251-256.

[19] Clarkson, P.J., Waller, S.D. and Cardoso, C. (2015) Approaches to Estimating User Exclusion. Applied Ergonomics, 46, 304-310.

https://doi.org/10.1016/j.apergo.2013.03.001

[20] Dong, H. (2019) Inclusive Design: Chinese Archives. Tongji University Press, Shanghai. 